\title{
O CASAMENTO REPUBLICANO NA CRÔNICA DE MACHADO DE ASSIS
}

\author{
MARIA LUZIA ALVES BRITO \\ Universidade Federal de Uberlândia \\ Uberlândia, Minas Gerais, Brasil
}

Resumo: Desde a proclamação da República, a regulamentação do casamento civil tornou-se questão recorrente na imprensa nacional. Transformar o matrimônio em um contrato estatal significava estabelecer direitos e deveres para homens e mulheres, enquanto cônjuges ou pais. Dessa forma, o Estado regulamentava a vida familiar privada como um todo. Na década de 1890, tais debates ocuparam a imprensa brasileira. No período, Machado publicava regularmente as crônicas intituladas "A Semana" na Gazeta de Notícias, em que o tema teve espaço privilegiado. Estudar esses textos é fundamental para a compreensão das novas configurações sociais na vida privada pós-proclamação da República, em especial devido à possibilidade de compreendê-los em conjunto com a obra machadiana, que sempre se debruçou sobre o papel social do matrimônio.

Palavras-chave: crônica; gênero; Machado de Assis; casamento

\section{THE REPUBLICAN MARRIAGE IN THE CHRONICLE OF MACHADO DE ASSIS}

Abstract: After the proclamation of the Republic, regulations for civil marriage became a recurring issue in the national press. Turning marriage into a state contract meant establishing rights and duties for men and women as spouses or parents. In this way, the country regulated the private family life as a whole. In the 1890s, these discussions occupied the Brazilian press. At the time, Machado regularly published a column entitled "A Semana" in Gazeta de Notícias, in which this topic was given priority. Studying these texts is fundamental for understanding the new social configurations in post-proclamation-of-the-Republic private life, especially because of the possibility of understanding them together with Machado's work, which always focused on the social role of marriage.

Keywords: chronicle; gender; Machado de Assis; marriage 


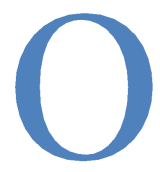

rdem urbana, controle sobre os corpos baseado em preceitos ditos "científicos", bem como a estagnação social foram temas que permaneceram na obra machadiana na década de 1890, apesar das significativas mudanças que o país atravessava, indicando as continuidades entre o fim do período imperial e o início do republicano. Desde a década de 1880, a produção de crônicas do autor crescia. Nos primeiros anos da República, diversos experimentos literários nesse gênero formaram a última e maior série que o literato produziria. Ao longo dos cinco anos de publicação da série "A Semana" (1892-1897), 247 textos ocuparam o espaço do editorial de domingo da Gazeta de Notícias, objetivando comentar os assuntos mais discutidos nos sete dias anteriores. O periódico funcionava como uma espécie de interlocutor primordial para a construção dos textos.

O espaço do editorial semanal, já tradicionalmente ocupado por séries de crônicas na Gazeta de Notícias, não contou com assinaturas antes ou depois de "A Semana". ${ }^{1}$ Apesar disso, a autoria de Machado de Assis era reconhecida em outros periódicos, que por vezes apresentaram críticas positivas à série. ${ }^{2}$ Durante toda a década de 1880, o autor dedicou grande parte do seu tempo na elaboração ficcional de narradores nas centenas de crônicas então publicadas. ${ }^{3} \mathrm{O}$ fato de ocupar o editorial e o impedimento de assinar aquele espaço não foram capazes de frear as experimentações literárias do autor, nesse gênero ainda em formação. Dessa forma, Machado construiu um narrador que, apesar da falta da assinatura, apresentou complexidade literária desde o início da série. As opiniões um tanto absurdas, o tom jocoso em relação aos problemas enfrentados pela República e a criação de personagens ficcionais secundários foram os principais recursos literários empregados na construção do último narrador das séries de crônicas machadianas.

A maior parte dos textos que formaram a série continha temas da esfera pública, como as reuniões parlamentares, projetos de lei, crimes, atuação policial, novidades científicas etc. Apesar disso, personagens femininas estiveram presentes na série trazendo para a discussão na imprensa destinada ao público amplo questões como contracepção, maternidade, direito ao voto,

\footnotetext{
${ }^{1}$ Para um levantamento completo sobre os usos desse espaço na Gazeta de Notícias antes e depois da série, ver SOUZA, Machado de Assis e a República de "A Semana": literatura, imprensa e práticas populares (1892-7).

${ }^{2}$ Gledson encontrou referência à autoria da série já em janeiro de 1893, quando Artur Azevedo indicou a qualidade literária desses textos, citando Machado como autor. Ver: GLEDSON, Por um novo Machado de Assis: ensaios.

${ }^{3}$ RAMOS, As máscaras de Lélio: política e humor nas crônicas de Machado de Assis. Ao analisar a construção de Lélio, a autora destaca o investimento machadiano no estatuto ficcional da crônica como marca da carreira do literato na década de 1880.
} 
violência nos relacionamentos românticos e matrimônio. A partir da intertextualidade da série e das experiências de Machado com os temas da esfera privada em outros periódicos, torna-se possível compreender as discussões sobre regulamentação do casamento civil e divórcio nos primeiros anos após a proclamação, considerando esse um período de reorganização jurídica da sociedade brasileira.

Na década de 1890 a Câmara dos Deputados e o Senado discutiam a regulamentação do casamento, divórcio e os direitos dos cônjuges frequentemente. Em 1891 foi promulgado o decreto que regulamentava o casamento civil, ${ }^{4}$ entretanto o texto era superficial e necessitava de complementos legais, que foram debatidos durante todo o período de publicação da série. Por outro lado, o decreto não foi bem aceito pela população em geral. A Igreja Católica, ao perder poder, acusava a República de ir contra as leis de Deus e conquistava apoio junto à população. ${ }^{5}$ Já nas páginas da Gazeta de Notícias muitas colunas continham argumentos prócasamento civil.

Em "A Semana", o narrador escolheu um processo jurídico para argumentar a respeito do tema. A investigação e o julgamento de um caso de bigamia ocorrido no Rio de Janeiro em 1894 foram terreno fértil para a argumentação do cronista. O capitão Manuel Ferreira de Louzada fora acusado pela própria esposa, Maria Carlota Amoretti Louzada. Durante o período de investigação, os progressos do caso foram detalhadamente narrados nas páginas dos periódicos cariocas. Desde meados de setembro de 1894 a Gazeta narrava o caso em pormenores, conforme as investigações avançavam. O depoimento do capitão Louzada, descrito na página inicial do periódico, demonstrava a pouca importância que o acusado dava ao caso, bem como sua desconsideração pela esposa. O réu alegava que Maria Carlota Amoretti Louzada estava morta e a mulher que apresentava a denúncia, passando-se por sua esposa, era na verdade sua cunhada. Segundo essa versão dos fatos, a irmã de Maria Carlota, de nome real Maria Augusta, teria assumido a identidade da irmã, quando a primeira faleceu, no ano de 1889. A troca entre as irmãs teria culminado no enterro da verdadeira Maria Carlota com o nome falso de Maria Augusta. Para completar a história chocante, a verdadeira

\footnotetext{
${ }^{4}$ REPÚBLICA DOS ESTADOS UNIDOS DO BRASIL, Decreto n. 181, de 24 de janeiro de 1890. Promulga a lei sobre o casamento civil; REPÚBLICA DOS ESTADOS UNIDOS DO BRASIL, Constituição da República (1891), art. 72, $₫ 4^{\circ}$.

${ }^{5}$ Sobre a resistência da Igreja em aceitar o casamento civil, ver: LOPES, Quod Deus conjuxit homo non separet: um estudo de gênero, família e trabalho através das ações de divórcio e desquite no Tribunal de Justiça de Campinas (1890-1938).
} 
esposa do capitão teria morrido enquanto se prostituía e a irmã que assumira o local da primeira teria sido, durante todo esse tempo, amante do capitão. Dessa forma, para safar Louzada da condenação da opinião pública, o capitão e seu advogado escolhiam culpar as supostas Maria Carlota e Maria Augusta pelo ocorrido; ou seja, Louzada não era bígamo, e sim viúvo, Maria Carlota era prostituta e Maria Augusta uma farsante. Em última instância, o capitão era apenas uma vítima das duas mulheres. Na Gazeta de Notícias, entretanto, a versão de Louzada foi duramente criticada. A acusação de prostituição em relação à própria esposa supostamente morta causou perplexidade entre os intelectuais do periódico, que duplicavam a culpa do réu: "Além do crime, o ultraje!". ${ }^{6}$

Outro aspecto da defesa de Louzada é fundamental para a compreensão do caso. O capitão afirmava que sua esposa falecera em 1889. Nesse ano a responsabilidade por julgar os casos de divórcio e/ou bigamia era do Tribunal Eclesiástico. Assim, ao depor contra a moralidade de Maria Carlota, Louzada utilizava-se de um argumento que poderia convencer um tribunal pautado em moralidade religiosa. A primeira esposa lhe teria dado, de acordo com a lei anterior ao Decreto n. 181, o direito de abandoná-la ao se prostituir. Já a amante/cunhada, que agora o acusava, seria culpada por se envolver com um homem que, apesar de divorciado, não poderia casar-se novamente. Entretanto, esse detalhe não passava despercebido e era motivo de críticas duras por parte da intelectualidade divorcista.

O depoimento de Louzada era material privilegiado para a confecção da crônica, e Machado aproveitou-se do tema com a finalidade de argumentar a favor do casamento civil por meio do narrador ficcional. Ao reapresentar o caso aos leitores, o cronista atribuía toda a confusão a uma possível reencarnação, aproveitando o ensejo para criticar também as já famosas teorias espíritas.

Sendo a doutrina verdadeira, está explicada a confusão da esposa, da cunhada e da senhora estranha, que se dá no processo do capitão, porquanto os doutores da escola ensinam que os espíritos renascem muita vez tortos, isto é, os filhos encarnam-se nos pais das mães, e não é raro ver um menino voltar a este mundo filho de um primo. Daí essa complicação de pessoas, que a polícia não deslindará nunca, sem o auxílio desta grande doutrina moderna e eterna.

Converta-se a polícia. ${ }^{7}$

${ }^{6}$ Bígamo, Gazeta de Notícias, 18 set. 1894, p. 1.

${ }^{7}$ A Semana, Gazeta de Notícias, 23 set. 1894, p. 1. 
O cronista relacionava a interpretação religiosa ao caso de bigamia, sendo que a principal argumentação desfavorável ao casamento civil e aos seus consequentes litígios era justamente a religiosa - no caso, católica. Ao aludir às disputas entre religiosos e republicanos no que dizia respeito ao Decreto n. 181 e à própria Constituição de 1891, o narrador conseguia ridicularizar as teorias espíritas que se pretendiam tão científicas, mesmo sendo religiosas. Em sentido mais amplo, ele exibia indiretamente a sua opinião sobre uma discussão importante no momento: a laicização do Estado. Na sequência, após tecer crítica ao serviço de bondes, ${ }^{8}$ o cronista voltava ao caso Louzada para finalizar o texto:

Voltando à bigamia do capitão, digo novamente à polícia que estude o espiritismo e achará pé nessa confusão de senhoras. Sem ele, nada há claro nem sólido, tudo é precário, escuro e anárquico. Se vos disserem que é vezo de todas as doutrinas deste mundo darem-se por salvadoras e definitivas, acreditai e afirmai que sim, excetuando sempre a nossa, que é a única definitiva e verdadeira. Amém. ${ }^{9}$

No início do trecho é possível ler que a confusão era atribuída, por parte do narrador, às mulheres envolvidas no caso, e não ao bígamo: "nessa confusão de senhoras". A regulamentação do casamento e a do divórcio apareceram frequentemente como problemas femininos. Intelectuais e leitoras eram convidadas a discutir as implicações desses projetos na imprensa. ${ }^{10} \mathrm{~A}$ possibilidade de encerrar o casamento como um contrato incluía a noção de que mulheres poderiam se ver obrigadas a sustentar suas famílias sozinhas, sem o controle dos maridos, mas também sem seu suporte financeiro. Esperava-se que um homem adulto se mantivesse financeiramente através do próprio trabalho independente de seu estado civil, portanto o divórcio implicava mudanças mais significativas na vida das mulheres. Em resumo, a mulher deveria cuidar do lar e dos filhos e manter-se sexualmente fiel ao

\footnotetext{
${ }^{8} \mathrm{Na}$ crônica o narrador dizia que ele mesmo seria o responsável por desenvolver melhor a teoria espírita. Em sua versão, os mortos reencarnariam também em objetos e em animais. A suposta teoria servia para criticar os serviços de bonde que, apesar das trocas de companhias, continuavam apresentando os mesmos problemas. Em suas palavras: "Quem disser, por exemplo, que o serviço da antiga companhia de bondes do Jardim Botânico está reencarnado no novo, provará com isso que de certo tempo a esta parte só tem andado de carro [...]" (Ibidem).

${ }^{9}$ Ibidem.

${ }^{10}$ Um exemplo é Júlia Lopes de Almeida, que chegou a ser chamada de divorcista em 1912, mas já estava debatendo o tema em periódicos para o público familiar anos antes. Ver: LOPES, cit., p. 112.
} 
marido. O homem, por sua vez, ficava obrigado a sustentar a família, controlar o acesso feminino ao trabalho e manter fidelidade, inclusive financeira, à esposa e aos filhos. Ao acusar o marido de adultério, Maria Carlota utilizava o mecanismo jurídico para obrigar o cônjuge a cumprir seus novos deveres civis, de acordo com a lei do casamento civil.

Ao mesmo tempo, Maria Henriqueta utilizava a mesma lei para garantir que as obrigações do capitão Louzada eram devidas a ela. Já no Código de 1830, as definições de adultério masculino e feminino eram distintas. ${ }^{11}$ Para se considerar uma esposa como adúltera, bastava que ela fugisse à obrigação da fidelidade conjugal, conceito um tanto amplo. Já para um marido ser visto como adúltero era necessário que ele vivesse em concubinato com outra mulher. ${ }^{12}$ Tal distinção derivava da ideia de que a obrigação da esposa no matrimônio era a fidelidade sexual que garantiria a legitimidade da prole, numa perspectiva patriarcal. ${ }^{13}$ Enquanto isso, a obrigação do marido era a de provedor financeiro, sendo que sua traição à família seria justamente oferecer sustento a outras pessoas. ${ }^{14}$ O Decreto de 1890 não mudava em nada as atribuições dos cônjuges, mantendo as posições sociais já tradicionais de marido e esposa intactas. Dessa forma, a suposta Maria Augusta e a viúva Maria Henriqueta poderiam ser vistas como moralmente condenáveis por suas relações com o capitão e, em casos extremos, poderiam ser juridicamente condenadas. Todavia, Louzada só era acusado por Maria Carlota porque faltara com a sua obrigação de marido: oferecia sustento a outra mulher, enquanto que a sua obrigação financeira era com a família que havia instituído legalmente.

O cronista defendia assim a posição de Maria Carlota. Evidenciando a necessidade de organizar legalmente as famílias brasileiras, a condenação ao comportamento de Louzada foi unânime em todas as colunas do jornal. $\mathrm{O}$ trecho anteriormente citado trazia ainda uma constatação final sobre o caso: cada um acreditava naquilo que melhor lhe aprouvesse, já que a única doutrina "definitiva e verdadeira" era sempre a própria doutrina pessoal de cada um. Dessa forma, o narrador encerrava seu texto apontando para o fato de que a bigamia já estava havia muito provada e a continuação da investigação servia apenas para manter o protocolo policial, pois era impossível acreditar em Louzada após tantas provas apresentadas e publicadas pela imprensa. A defesa de Maria Carlota era a própria defesa do casamento civil, da necessidade de

\footnotetext{
${ }^{11}$ PAPALEO, Dom Casmurro: estudo sobre as relações conjugais no Brasil do final do século XIX.

12 Idem.

${ }^{13}$ HIRATA; KERGOAT, Divisão sexual do trabalho profissional e doméstico: Brasil, França, Japão.

${ }^{14}$ OLIVEIRA, A construção social da masculinidade, p. 151.
} 
garantir direitos e deveres predeterminados para os cônjuges e, consequentemente, punições para aqueles que não cumprissem a lei.

Mil oitocentos e noventa e seis foi um ano marcante para a discussão do divórcio. O deputado Érico Coelho apresentou a segunda versão de seu projeto de lei sobre o divórcio na Câmara, sendo novamente recusado. ${ }^{15}$ No Senado, a polêmica ficou por conta de Coelho Rodrigues. O então senador do Piauí pautara boa parte do projeto, ao qual dedicara anos de sua carreira, na noção de que um casamento infeliz prejudicava não somente os casais, mas poderia causar problemas a toda a sociedade. Nas palavras do político:

Com efeito, ninguém pode negar o fato da existência de muitos casais, cuja convivência tornou-se impossível, nem sustentar que a autoridade pública possa manu militari obrigar a viverem juntos os cônjuges que se tornaram irreconciliáveis e muito menos negar que essa convivência, ainda que pudesse ser imposta à força, deixasse de ser uma fonte de corrupção e aviltamento para a prole, de vergonha para a família de ambos, de escândalos para a sociedade e de perigos para a ordem pública. ${ }^{16}$

O projeto de 2 de julho de 1896 era, provavelmente, o mais polêmico, pois trazia pela primeira vez a possibilidade de dissolução total do vínculo matrimonial, garantindo o direito a novo casamento, com raras exceções que dependiam de condenação judicial. Periódicos dedicados às famílias incentivaram suas leitoras a encaminharem cartas ao Senado Federal criticando o projeto. ${ }^{17} \mathrm{Na}$ Gazeta de Notícias constava o texto "O divórcio no Senado", que tomou conta de quatro colunas da primeira página. Ao invés de discorrer diretamente a respeito do projeto, o periódico optou por analisar a réplica do senador maranhense Gomes de Castro ao projeto divorcista de Coelho Rodrigues. A Gazeta considerava os argumentos antidivórcio excessivamente moralizadores e juridicamente contraditórios.

Segundo a folha, Gomes de Castro se apoiava na noção de que os projetos que regulamentavam o divórcio, bem como o próprio decreto n. 181 não eram adequados à moralidade das famílias brasileiras. Para o senador, mesmo nos casos de adultério e tentativa de uxoricídio, o divórcio deveria ser abolido.

\footnotetext{
15 LOPES, cit.

16 BRASIL. CONGRESSO NACIONAL. SENADO FEDERAL, Diários do Congresso Nacional: República dos Estados Unidos do Brazil. Sessão de 2 de julho de 1896, p. 1. Apud ROCHA, Amor, Ordem e Progresso: casamento e divórcio como desafios à laicidade do Estado (1847-1916).

${ }^{17}$ ROCHA, cit.
} 
Para a Gazeta, essas eram considerações ilógicas, pois se as famílias estivessem, de fato, ameaçadas pela regulamentação do divórcio, elas não seriam "tão moralizada[s]"18 quanto o senador dizia. Além disso, se a Constituição definia o casamento como mero contrato, ele deveria ser passível de dissolução, como qualquer outro. $\mathrm{O}$ argumento final era o de que a mulher desquitada, assim como a viúva, vivia os perigos de precisar manter-se financeiramente - e também manter os filhos - sem o auxílio de um homem, enquanto que o divórcio poderia resolver tal problema, pois permite que: "a mãe de família [em comparação com a viúva], a quem a morte roubou o amparo dos filhos, contraia novo casamento, quando mais não seja, para acabar de criar e educar a prole do primitivo!". ${ }^{19}$

Havia ainda críticas aos políticos que se abstinham da discussão. Ao citar Coelho Rodrigues como "tão digno pai de família quão jurisprudente conceituoso", 20 a Gazeta atentava para a covardia dos deputados diante da proximidade das eleições. A coluna de título "Divórcio" afirmava que os senadores estavam tentando adiar a votação ou simplesmente rejeitar o projeto de Coelho Rodrigues "no temor de que o clericalismo pinte o diabo, contra os divorcistas". ${ }^{21} \mathrm{O}$ jornal defendia que se era interesse do Estado não ter qualquer dependência da Igreja, era obrigação dos senadores enfrentar o clero, quando este se opusesse ao andamento das leis nacionais.

O tema voltaria às crônicas machadianas após a derrota do projeto. Novamente o autor optava por relacionar casamento civil e religião. Com esses elementos, o narrador criticaria a falta de aptidão da juventude para lidar com a lógica de dominação senhorial, o aspecto financeiro que dominava as escolhas matrimoniais e a absurda reivindicação espírita de um estatuto científico para a doutrina religiosa. Como um fio condutor, o narrador falaria das dificuldades econômicas no país. ${ }^{22}$ Já de início, a crônica relacionava novamente religião e divórcio:

[...] vai chegar o amor livre, se é verdade o que me anunciou, há dias, um espírita. [...] O amor livre acompanha os estados da alma; pode durar cinco anos, pode não passar de seis meses, três semanas ou duas. Aos

\footnotetext{
${ }^{18}$ O divórcio no Senado, Gazeta de Notícias, 17 jul. 1896, p. 1.

${ }^{19}$ Ibidem.

${ }^{20}$ Divórcio, Gazeta de Notícias, 24 jul. 1896, p. 1.

${ }^{21}$ Ibidem.

22 FRANCO, A economia em Machado de Assis: o olhar oblíquo do acionista.
} 
valsistas plena liberdade. O divórcio, que o senado fez cair agora, será remédio desnecessário. Nem divórcio nem consórcio. ${ }^{23}$

A relação servia para vincular o debate à pressão dos setores religiosos, mas também para tecer uma crítica aos senadores. O narrador usava o argumento mais simples que o periódico apresentara: Se o Senado não se importava em legislar sobre a questão, a população se incomodava ainda menos. Além disso, a alusão ao "amor livre" era também uma forma de lembrar que a impossibilidade do divórcio como ferramenta para dissolução dos vínculos matrimoniais era contra o princípio da liberdade, como o jornal defendera nas semanas anteriores.

No mesmo texto, o cronista trataria do caso de tentativa de suicídio de um adolescente carioca que se dizia apaixonado por uma vizinha. O narrador iniciava a crônica citando o romance Paulo e Virgínia (1787) do francês Bernardin de Saint-Pierre. A obra narra a história de duas crianças que, tendo sido criadas juntas numa ilha afastada da civilização francesa, não entram em contato com os perigos morais da Corte. Virgínia, na adolescência, é levada para o continente por uma tia para receber a educação das moças de alta sociedade. Enquanto isso, Paulo sofre a ausência da menina, por quem se descobre apaixonado. Quando Virgínia tenta retornar, o navio no qual a moça está naufraga, e Paulo assiste à morte da jovem. Num clássico final romântico, o rapaz falece ao constatar a perda de sua amada. O romance de Saint-Pierre ficou reconhecido por trabalhar com a concepção de "bom selvagem" de Rousseau.

A pureza do amor de Paulo e Virgínia foi uma excelente representação do romantismo e também duramente criticada pelos realistas. A personagem Ema Bovary passa boa parte da polêmica obra de Gustave Flaubert procurando encontrar um Paulo, o que se mostra impossível. O narrador da série utilizou então a história de um casal real, Alfredo e Laura, para contrastar com a romântica narrativa francesa:

Avizinham-se os tempos. Este século principiado com Paulo e Virgínia, termina com Alfredo e Laura. Não é já o amor ingênuo de Port-Louis, mas um idílio trágico, como lhe chamou a Gazeta de anteontem, sem dúvida para empregar o título do último romance de Bourget. ${ }^{24}$

\footnotetext{
${ }^{23}$ A Semana, Gazeta de Notícias, 2 ago. 1896, p. 1.

${ }^{24}$ Ibidem.
} 
O número de 31 de julho da Gazeta de Notícias trazia, no centro da segunda página, a coluna indicada pelo narrador. O texto dizia que o jovem Alfredo, de cor parda, catorze anos, empregado de uma fábrica de móveis, tentara se matar com um tiro no ouvido na frente da casa de Laura, também parda, de treze anos, empregada em casa de família. O tom literário, comum na Gazeta, destacava-se na coluna:

Ontem, às 11 horas da manhã, declarou na casa em que era empregado, que se achava doente, e por essa razão se retirava para sua residência. Aí chegando, foi a uma estante e, tirando um revólver, encaminhou-se para a casa de sua adorada Laura. Por longo tempo, segundo nos informam, levou a passear alegremente pela frente da casa onde ela mora, até que às 3 horas da tarde conseguiu falar-lhe e disse-lhe que, visto não ser correspondido em seus amores, ia dar cabo da vida. Laura pouca importância ligou às palavras de Alfredo e retirou-se. [...]

Algumas pessoas que na ocasião passavam, e moradores da rua de S. Luiz que ouviram a detonação, trataram imediatamente de socorrer a infeliz criança $[. ..] .{ }^{25}$

Apesar da comiseração do jornal para com o jovem, o narrador da série criticaria tal comportamento. A ideia de que a recusa da moça fosse motivo para o rapaz se matar não fazia sentido para o cronista. É importante observar não somente o engajamento de Machado nas discussões sobre o realismo, ${ }^{26}$ como também a longa trajetória do autor a trabalhar com o caráter econômico/financeiro das convenções sociais do casamento no Brasil. Machado havia trabalhado com a temática do casamento por décadas em contos e romances. Cilene Pereira salientou, por exemplo, a imagem de fracasso do matrimônio nos Contos fluminenses (1870) e nas Histórias da meianoite (1873). Para a autora, os contos reunidos nos dois livros tinham essa

${ }^{25}$ Idílio Trágico, Gazeta de Notícias, 31 jul. 1896, p. 2.

${ }^{26}$ Ver: RAMOS, A batalha de Machado de Assis, cit. A autora destaca a polêmica dos comentários de Machado sobre O Primo Basílio de Eça de Queiroz, argumentando que, a despeito da conclusão de muitos dos críticos da obra machadiana, as duras opiniões de Machado não significavam exatamente uma aversão ao realismo ou apego ao romantismo, mas uma visão política do autor sobre as escolas literárias, além da óbvia crítica estética. As análises do autor recaíam também sobre o naturalismo que, para ele, se apegara à noção moderna de estatuto científico como sinônimo de verdade. Dessa forma, o "realismo" parecia não funcionar como narrativa tão capaz de apreender a realidade como os literatos adeptos queriam fazer parecer. A crítica de Machado, assim, é parte de uma batalha que o autor assumiria como parte fundamental de sua carreira. Outros autores como John Gledson demonstraram como a obra de Machado foi marcada por avaliações criteriosas da sociedade brasileira, mesmo que de forma pouco tradicional para a escola realista. Ver GLEDSON, Machado de Assis: impostura e realismo: uma reinterpretação de Dom Casmurro. 
temática central, mesmo que alguns trabalhassem com os mecanismos sociais de arranjo dos casamentos, enquanto outros lidavam com a vida conjugal. Além de lidar com as imposições sociais, as mulheres tinham que enfrentar as decepções da realidade do matrimônio, em que os pretendentes eram, na verdade, homens interesseiros e, em comparação aos heróis românticos da literatura com a qual elas estavam acostumadas, eram também mesquinhos. ${ }^{27}$ Apesar de concordar com a perspectiva adotada pela autora, cumpre ressaltar que houve, na obra de Machado, outro ponto geral importante sobre o casamento: muitas das personagens femininas construídas pelo literato compreendiam os significados financeiros do matrimônio e, versadas a respeito das engrenagens sociais, utilizavam as relações matrimoniais - e até extramatrimoniais -, para alcançarem seus objetivos ou conquistarem vantagens. Essa perspectiva é importante para compreender a série, pois ao argumentar a respeito da necessidade de dessacralizar o casamento, transformando-o no contrato civil adequado para o sistema republicano, o autor criticava novamente a noção romântica de matrimônio. Essa crítica servia, portanto, para evidenciar que, na prática, o amor era mesmo mais próximo de um contrato do que dos ideais românticos.

Diversas possibilidades de interpretação dos contos machadianos das décadas de 1870 e 1880 foram destacadas pela pesquisadora Daniela Silveira. Ao analisar a abordagem de Machado a respeito da ciência nos periódicos dedicados ao público feminino, a autora argumentava que boa parte desses textos discorria sobre o papel feminino no matrimônio. Assim a construção das senhoras - e de seus senhores - contribuía para levantar questionamentos entre leitores e leitoras a respeito da atuação feminina dentro da lógica de domínio senhorial do matrimônio. ${ }^{28}$ Dessa forma, o argumento da pesquisadora nos auxilia a perceber como era importante para o autor discutir o papel masculino nas relações conjugais. O caso do jovem que justificava a tentativa de suicídio através da recusa da vizinha demonstrava o despreparo da juventude pobre diante do jogo social que era o casamento no século XIX.

Se Machado havia dedicado grande parte da sua carreira a construir análises da ideologia senhorial, o narrador da série "A Semana" era um homem muito ciente desses mecanismos sociais. Compreendendo as poucas e complexas possibilidades de manobra dentro dessa ideologia, o autor levara anos fabricando personagens das camadas menos abastadas que venciam

\footnotetext{
27 PEREIRA, Jogos e cenas do casamento: construção e elaboração das personagens e do narrador machadianos em Contos fluminenses e Histórias da meia-noite, p. 54.

${ }^{28}$ SILVEIRA, Fábrica de contos: ciência e literatura em Machado de Assis, p. 225-245.
} 
barreiras por inteligência e domínio dos meandros sociais. Há, no Brasil do século XIX, uma hierarquia social que é tão rígida quanto complexa. Os personagens ficcionais de Machado, quando pertencentes às classes populares, precisam lidar com essa lógica, e grande parte das mulheres da obra machadiana consegue fazê-lo com louvor. ${ }^{29}$

Se há um traço biográfico no romance machadiano, esse é perceptível na forma como o escritor torna central o destino dos dependentes. Não transpôs seu caso particular de mulato dependente para suas histórias, mas o transmutou do aspecto racial para o de gênero. ${ }^{30}$

Sendo esta uma temática querida pelo autor, o narrador da série, cronista de meia-idade, acomodado e interesseiro, se chocava com a dificuldade de um jovem trabalhador, vindo da classe baixa, conseguir lidar de forma mais contundente com uma relação amorosa. Desse modo, a crônica seguia argumentando que havia formas melhores (e mais lucrativas) de encarar os primeiros percalços do amor:

[...] Em verdade, esse adolescente de catorze anos, que procurou a morte por não poder vencer os desdéns da vizinha de treze anos, faz temer a geração que aí vem inaugurar o século XX. Que os dois se amassem, vá. [...] Que ela não gostasse dele, também é possível. Nem todas elas gostam logo dos primeiros olhos que as procuram; em tais casos, [...]. Mas aquela aurora de sangue, aquela tentativa de fazer estourar a vida, na idade em que tudo manda guardá-la e fazê-la crescer, eis aí um problema obscuro $[\ldots] . .^{31}$

Problema obscuro este que fazia o cronista recear pelos jovens. Para o narrador, o romantismo dos adolescentes não fazia sentido prático. Ao mesmo tempo, relacionar imaturidade com as votações sobre o divórcio deixava entrever uma nova crítica: a noção de que o casamento é mais do que um contrato - algo sagrado ou moralmente superior, que não pode ser dissolvido - ficava comparada à infantilidade. No fim, o casamento civil tinha um valor

\footnotetext{
29 É preciso ressaltar aqui as análises de Helena e Iaiá Garcia produzidas por Sidney Chalhoub na obra CHALHOUB, Machado de Assis: historiador. O autor dedicou o livro a compreender as relações de dependência e a lógica de dominação/subordinação senhorial na obra de Machado. Os dois primeiros capítulos destacam especialmente as duas obras citadas acima.

30 MISKOLCI, O desejo da nação: masculinidade e branquitude no Brasil de fins do XIX, p. 89. É importante destacar que a reflexão do autor é baseada na obra de Roberto Schwarz, que discutiu a questão em Ao vencedor as batatas.

${ }^{31}$ A Semana, Gazeta de Notícias, 2 ago. 1896, p. 1.
} 
econômico, que homens adultos - entre eles, os senadores - deveriam entender claramente.

Em 1896, o narrador voltaria ao tema da regulamentação do casamento. Ao analisar a legislação municipal que proibia explosões na pesca, o narrador desenvolvia pequena teoria sobre o sentido das leis:

[...] A utilidade das leis escritas está em regular os atos humanos e as relações sociais, uma vez que vão de acordo com eles. Em chegando o desacordo, há dois modos de as revogar ou emendar, a saber, por atos individuais ou por adoção de leis novas. No capítulo do divórcio, por exemplo, não existindo pretoria que case um homem já casado, o remédio para obtê-lo é decretá-lo. [...] Resta aos partidos convencidos da necessidade dela continuar a propaganda até pô-la na lei. ${ }^{32}$

Para o narrador, o problema era que as leis deveriam seguir aquilo que fosse "necessário para conjugar os interesses humanos, que são a base da harmonia social". ${ }^{33}$ Portanto, se havia interesse, por parte dos homens, em casar-se duas vezes, deveria haver decreto que o autorizasse. Ao reduzir a discussão à simples vontade dos homens, o narrador gerava polêmica, mas também ironizava os argumentos antidivórcio, considerando que de toda forma, com a propaganda dos partidos favoráveis, o divórcio seria posto em lei. Numa leitura mais atenta da crônica era possível concluir que o próprio decreto de 1890 fora pensado dessa forma: se os casamentos já se desmanchavam de fato, não havia problema em criar forma legal para desfazêlos juridicamente. Todavia, o decreto não dava conta da realidade, não considerava os problemas matrimoniais que culminavam no fim de um casamento, não pensava na condição da mãe de família ou dos filhos após o término.

Para os leitores que viam diariamente os debates sobre o divórcio na imprensa, colocar na mesma crônica uma consideração sobre o divórcio e uma discussão sobre o modo como leis eram feitas significava uma forma de levantar debates. Se a Lei do Pescado visava a impedir que os explosivos fizessem mal à saúde dos consumidores, em que é que o decreto n. 181 afetava a população? Se os pescadores já usavam mesmo a dinamite, a Lei do Pescado previa punição. Se os casais se uniam sem autorização legal da República e constituíam famílias sobre as quais o Estado não conseguia manter controle, o que os projetos que previam regularização desses casamentos sem quaisquer

${ }^{32}$ A Semana, Gazeta de Notícias, 25 out. 1896, p. 1.

${ }^{33}$ Ibidem. 
punições estavam fazendo? Enquanto a Gazeta se dedicara por meses a discutir a inconstitucionalidade de impedir os divórcios, Machado usava uma comparação simples para demonstrar o mesmo problema legal.

Pela própria definição da crônica oitocentista, gênero ainda em experimentação, a série foi marcada pela leveza mesmo nos temas mais complexos. A regulamentação do casamento civil e seus desdobramentos legais influenciavam diretamente os projetos de país que estavam sendo debatidos nos primeiros anos após a proclamação da República. Machado foi, senão um adepto dos projetos divorcistas, ao menos um grande crítico da argumentação antidivórcio. Esses textos depõem não somente sobre o debate a respeito dos direitos e deveres das mulheres do fim do século, mas também sobre os limites dos papéis imaginados para as mulheres brasileiras no início do período republicano.

\section{Referências}

CHALHOUB, Sidney. Machado de Assis, historiador. São Paulo: Companhia das Letras, 2003.

FRANCO, Gustavo. A economia em Machado de Assis: o olhar oblíquo do acionista. Rio de Janeiro: Jorge Zahar, 2007.

GAZETA DE NOTÍCIAS. Rio de Janeiro, 1892-1897.

GLEDSON, John. Machado de Assis: impostura e realismo: uma reinterpretação de Dom Casmurro. São Paulo: Companhia das Letras, 1991. 2006.

. Por um novo Machado de Assis: ensaios. São Paulo: Companhia das Letras,

HIRATA, Helena; KERGOAT, Danièle. Divisão sexual do trabalho profissional e doméstico: Brasil, França, Japão. In: COSTA, Albertina de Oliveira et al. (orgs.). Mercado de trabalho e gênero: comparações internacionais. Rio de Janeiro: Editora FGV, 2008, p. 263-278.

LOPES, Cristiane Fernandes. Quod Deus conjuxit homo non separet: um estudo de gênero, família e trabalho através das ações de divórcio e desquite no Tribunal de Justiça de Campinas (1890-1938). 2002. 203 f. Dissertação (Mestrado em História Econômica) - Faculdade de Filosofia, Letras e Ciências Humanas, Universidade de São Paulo, São Paulo, 2002.

MISKOLCI, Richard. O desejo da nação: masculinidade e branquitude no Brasil de fins do XIX. São Paulo: Annablume, 2013.

OLIVEIRA, Pedro Paulo de. A construção social da masculinidade, vol. 22. Belo Horizonte: Editora UFMG, 2004. 
PAPALEO, Marcia Kern. Dom Casmurro: estudo sobre as relações conjugais no Brasil do final do século XIX. 2014. 98 f. Dissertação (Mestrado em Letras) - Instituto de Letras, Universidade Federal do Rio Grande do Sul, Porto Alegre, 2014.

PEREIRA, Cilene Margarete. Jogos e cenas do casamento: construção e elaboração das personagens e do narrador machadianos em Contos fluminenses e Histórias da meia-noite. 2008. 291 f. Tese (Doutorado em Teoria e História Literária) - Instituto de Estudos da Linguagem, Universidade Estadual de Campinas, Campinas, 2008.

RAMOS, Ana Flávia Cernic. As máscaras de Lélio: política e humor nas crônicas de Machado de Assis. Campinas: Editora da Unicamp, 2016.

REPÚBLICA DOS ESTADOS UNIDOS DO BRASIL. Constituição da República (1891), art. $72,94^{\circ}$.

—. Decreto n. 181, de 24 de janeiro de 1890. Promulga a lei sobre o casamento civil.

ROCHA, Ana Vitória Sampaio Castanheira. 2014. 129 f. Amor, Ordem e Progresso: casamento e divórcio como desafios à laicidade do Estado (1847-1916). Dissertação (Mestrado em História) - Instituto de Ciências Humanas, Universidade de Brasília, Brasília, 2014.

SILVEIRA, Daniela Magalhães da. Fábrica de contos: ciência e literatura em Machado de Assis. Campinas: Editora da Unicamp, 2010.

SOUZA, Ana Paula Cardozo de. Machado de Assis e a República de "A Semana": literatura, imprensa e práticas populares (1892-7). 2015. 243 f. Dissertação (Mestrado em História Social) - Instituto de Filosofia e Ciências Humanas, Universidade Estadual de Campinas, Campinas, 2015.

MARIA LUZIA ALVES BRITO é mestra em História pela Linha de Pesquisa "História e Cultura" do Programa de Pós-Graduação em História da Universidade Federal de Uberlândia, onde estuda História das Mulheres, imprensa e literatura brasileira no fim do século XIX. E-mail: malualvesbr@outlook.com. 